\title{
Web 2.0 Tools in the Innovation Process A Systematic Literature Review
}

\author{
Loay ALTAMIMI \\ Assist. Prof. at AL-Zaytoonah University of Jordan \\ Faculty of Economics and administrative Sciences \\ Dept. Management Information Systems \\ drlotamimi@gmail.com
}

There is a wide recognition that, innovation is a key and strategic process, that is, essential for the survival and growth of individual firms, and also, for sustainable national and regional economic growth. Meanwhile, on the one hand, collaboration is a necessary approach for the innovation process in today's environment, and, on the other hand, information technology (IT) tools are indispensable means for collaboration across different boundaries. Web 2.0 is a new generation of web tools that are providing new ways for work and new opportunities for interaction and collaboration. These new tools are increasingly being used by various organizations to enhance collaboration, to the end of, supporting and improving the innovation process. This review aims to assess the extent and scope to which the literature has examined web 2.0 tools in the context of the innovation process. For this purpose, scholarly articles, published from 2002 to 2012, on each of the topics of innovation and web 2.0, were collected by the literature search. The study here adopted the systematic approach of lexical analysis for extracting relevant articles from the corpus and for the analysis of those articles.

Keywords: Innovation, Collaboration, Web 2.0, Lexical Analysis, Literature Review

\section{1} Introduction

Innovation is not a new phenomenon. Arguably, it is as old as mankind itself. There seems to be something inherently "human" about the tendency to think about new and better ways of doing things and try them out in the practice. Without it, the world, in which we live, would look very different'. [1]

There is a wide recognition that, innovation is essential for the survival and growth of individual firms, and also for sustainable national and regional economic growth [2] [3]. According to the Boston consulting group innovation 2010 survey of 1600 senior executives representing a large number of countries and all major industries, innovation remains a top strategic priority for $72 \%$ of the executives surveyed [4]. Firms in today competitive and fast changing world are in a continuous need to identify new opportunities and seize them by developing and introducing new products and services. The OECD states that 'because global competition has intensified; companies have been forced to innovate more quickly and develop commercially viable products and services more rapidly' [5]. In knowledge-based economies; innovation is a major driver of growth [6]. It is the sole competitive advantage that is adaptable to any situation. It enables firms to create products and services and distinguish them from those of its competitors and thus obtain a global competitive advantage in the face of the global intense competition [7].

On another front, information technologies (IT) like the web have permeated the various aspects of organizational life, offering many possibilities of work, and the innovation process has not been an exception. For instance, the rapid developments in these technologies have resulted in that some barriers to the dispersion of $R \& D$ have become less significant [5]. The penetration of ITs into the dynamics of the innovation process makes the relation of these technologies and the innovation process an important subject that deserves attention and is worth investigation. The reference [8] states that, 'in this era, innovation is the main driver for competitiveness and using in- 
formation and communication Technologies (ICTs) is the basic requirement to conduct business. Therefore, better understanding of the relationship between use of IT and innovation has emerged as an important research topic'. However, a wide variety of tools may come under the rubric "ITs". These tools have different functions and characteristics, which presumably makes their roles and contribution to the innovation process different. IT Tools enabling interaction and collaboration are especially important in this context. These tools are critical to support crossboundary, cross-time and cost-effective collaboration [9] [10], and collaboration, in its turn, is 'the meta-capability that enables exploiting knowledge to drive innovation' [11]. Indeed, the influence of ITs on collaboration in the innovation process is evident in the "fifth-generation innovation" model (See [12] [13] [8]), as well as in the new paradigm of "open innovation" (cf. [14] [15] [16]). The attention given to the potentials of IT tools for collaboration, especially webbased tools, is manifested in employing these tools by many firms to enhance and support collaborative innovation ( $c f$. [17]). Particularly, in this context, web 2.0 is a new generation of web-based tools that enable interaction and collaboration. These new tools are increasingly being utilized as ways for businesses to collaborate and share information with employees, customers, partners and suppliers [18]. Specifically, various organizations are taking advantage of these tools, to improve collaboration, to the end of, improving the innovation process. [19] [20] [21]

\section{Background}

\subsection{Collaboration in the Innovation Pro- cess}

The role of knowledge is pivotal throughout the innovation process. In fact, innovation is characterized as a knowledge-intensive process, where different types of knowledge are retrieved, applied and created in the various activities of the process [22] [23]. The reference [11] sees knowledge as the key asset of the currently emerging innovation era.
'Knowledge lies at the very heart of this process. A firm's ability to create, store and transfer knowledge about technologies, customer needs, and the innovation process itself may well determine success in bringing new products or services to the market' [24]. In today's world, knowledge is growing and transferring around the globe in an accelerating pace [11]. Moreover, ideas are no longer confined just to a firm's internal boundaries. Knowledge can also be sourced from the external environment [25]. According to [26], 'External sources were not only prevalent in the ranking of CEOs' most significant sources of ideas, they also comprised a substantial portion of the overall quantity of ideas.....Companies with higher revenue growth reported using external sources significantly more than slower growers....When extensive collaborators' responses were examined by industry, the split between internal and external ideas appeared fairly even'.

It is vital to see innovation as both internally generated to maintain internal learning and the development of technological competence as well as externally generated to avoid the effect of "not invented here", which results in that, good ideas from outside are resisted or rejected [27]. The importance given to internal and external knowledge in innovation can be clearly seen in the new paradigm of 'open innovation'. Henry W. Chesbrough, who coined this term, defines it as 'a paradigm that assumes that firms can and should use external ideas as well as internal ideas, and internal and external paths to market, as they look to advance their technology. Open Innovation processes combine internal and external ideas into architectures and systems' [28].

Internal and external collaboration is a necessity for reaching out to and combining both internal and external knowledge. Effective knowledge creation, transfer, and utilization to foster innovation heavily depend on the ability to collaborate, both inside and outside the organization [11]. Collaboration is a necessary antecedent of knowledge creation and transfer, and the collaboration ca- 
pability, in other words, the ability to build and manage relationships with other parties on individual, team, departmental and organizational levels, is paramount in the search for continuous innovation [29].

Technological knowledge is vital for innovation, yet, it is by no means sufficient to maintain sustainable competitive advantage. There is a need for complementary knowledge to generate innovative ideas for products and services [29]. The various kinds of knowledge and information are often exchanged between organizations (suppliers, customers, competitors, universities, research institutes, etc.) in the form of collaboration, which is not mediated by the market. Thus, through their innovative activities, firms mostly embark upon collaborative relations with each other and other kinds of organizations [30].

Lastly in this part, collaboration is considered the meta-capability that enables exploiting knowledge to drive innovation. The know-how to collaborate helps a firm to create and transfer knowledge, which, in turn, lead to innovation. Firms that appreciate this long-linked process, and make the necessary investments needed to establish and maintain it, will be the big winners in the global economy [11].

\subsection{Collaborative Technologies in the In- novation Process}

In general, information and communication technologies (ICTs) have an undeniable impact on the organizational processes and dynamics. According to [31], this impact is on both workers and organizations, and it extends along the four dimensions working time, working place(s), type of contract and work content (applied skills). Specifically, Information technology tools powered by networking technologies, play a critical role in enabling cross-boundary, cross-time and cost-effective virtual ways of interaction and collaboration within and between organizations [9] [10].

As far as the innovation process is concerned, [9] states that, 'new communication and collaboration platforms, media, and tools are revolutionizing collaborative innovation as they now allow many-to-many collaboration at a scale and cost that could never have been achieved in the past. The Internet, an overnight success three decades in the making, along with its younger cousin the Web, really does change everything. For the first time, we now have tools that enable the free exchange of information across many individuals with remarkably low friction'.

The use of ITs to support internal and external collaboration in the innovation process is an essential characteristic of Roy Rothwell's 'fifth-generation innovation' model [12] [13] [8]. Also, these technologies have played an important role in spreading the open innovation model, as they have reduced the perceived distances between the actors of the innovation process while enabling integration of customers and suppliers into the design and development process [14].

Indeed, ITs do have a real potential to support collaborative $R \& D$ in inter-firm collaborative innovation projects (See [32]). Also, these technologies facilitate the collaboration, communication and coordination of new product development teams [33]. Equally significant, 'the emergence of new ITs has initiated a radical transformation of customer-producer relationships in many industries, with important implications for new product development(NPD)... customers can be involved not only in generating ideas for new products but also in co creating them with firms, in testing finished products and in providing end user product support' [34].

Particularly, web-based applications have a clear impact on collaboration in innovation. This may be because they could simplify the search for partners and facilitate rapid information exchange as well as they can be used to create a knowledge base that will lead to greater cohesion in the working group [32]. In this respect, web 2.0 is the new generation of web-based applications. It is a recent new wave of significant changes in the ways internet users and companies 
utilize the World Wide Web [35]. Web 2.0 applications are creating new ways of work and new opportunities for interaction and collaboration. Over the last several years, a variety of these applications has been widely adopted by individual users. Also, an increasing number of organizations _ which we elaborate on below _ have started utilizing such applications in hopes of boosting collaboration and driving innovations [19] [20] [21].

\section{Web 2.0 in the Innovation Process}

'The Internet and the Web are evolving to a platform for collaboration, sharing, innovation and user-created content-the so-called Web 2.0 environment' [36].

The term "Web 2.0", became notable after the first O'Reilly media Web 2.0 conference in 2004. As to the term "Social Software", it was popularized by Clay Shirky, starting in about 2002 [37]. However, the two terms, as in the context of this paper, are sometimes used synonymously (see e.g. [38] [39] [40]). Web 2.0 or social software refers to 'various, loosely connected types of applications that allow individuals to communicate with one another and to track discussions across the web as they happen' [41]. For more definitions see [40].

As indicated previously, knowledge has a pivotal role throughout the innovation process. Meanwhile, knowledge generation and transfer is a product of social exchange [11] [29]. Social interaction and collaboration are important for the enlargement of an individual's knowledge within an organization and thus initiating the process of organizational knowledge creation [42]. This is particularly significant, given that, innovations, by nature, emerge in social interaction in which diverse actors share complementary knowledge and collaboration is considered a prerequisite for actors to leverage such knowledge [29]. In this respect, web 2.0 technologies are rewriting the rules of social interaction, and the way business is conducted. New and ingenious methods of social interaction across geographic borders and industry silos are being created, as cited in
[43]. It is important here to draw a distinction between web 2.0 and conventional collaborative software (groupware). Web 2.0 or Social software is the opposite of what groupware and other project- or organization-oriented collaboration tools were intended to be. Social software is based on supporting the desire of individuals to be pulled into groups to achieve their personal goals. The groupware approach places people into groups defined organizationally or functionally [41]. (For more on the distinction between, social software and conventional collaborative software (groupware), see also, [44] [45]).

Indeed, the unique characteristics of web 2.0 or social software tools have made many organizations, as above-indicated, adopt these new technologies to foster collaboration and thus boost innovation processes. These important characteristics include knowledge sharing is voluntary [45], support for social networks, user-generated content, enforcing much less sense of hierarchy than in the real world so anyone can provide feedback or comments to anyone else and one person can be at the same time part of several networks [40] [46] [47], and establishing of weak ties, which refer to acquaintances with less social involvement, more superficial and on a smaller, less intimate basis [48]. Another essential characteristic is what is called "Nutzungsoffenheit", which implies that, it is hard to predict how a platform will be, appropriated [49], and whereby, technology and its set of features do not precipitate its forms of usage [50]. Values like transparency, cooperation, openness, ease of use are at the heart of the social web, and, all of them are heading towards the building of an architecture of participation, that is, focused on the users, and that, harnesses collective intelligence and uses network effects and algorithms to produce software that gets better the more people use it [20].

According to the Gartner report, "enterprises continue to invest in social software, because they need to support, more fluid communications, improve visibility across their organizations, stimulate idea sharing, and support expertise location and infor- 
mation sharing within teams and around projects [51]. The reference [52] shows a very significant increase in the use of Web 2.0 applications within companies. Specifically, as far as the innovation process is concerned, the interest in these emerging tools is manifested in the recently emerged term of Innovation 2.0, which refers to, the utilization of Web 2.0 platforms to support open innovation networks [53].

In this context, it is also noteworthy

that, web 2.0 tools are being used in many crowd-sourcing projects on the internet (see e.g. [54]). According to [35], the web 2.0 phenomenon has impacted on the concept of user-added value including user-generated content and user-generated creativity, as well as user-generated innovations and sources of revenue (see below, Table 1). In fact, the application of social software in innovation initiatives can be seen in different sectors as, for example, in the business-tobusiness (B2B) sector and the business-tocustomer (B2C) sector (see e.g. [55] [56]).

Table 1. Impact of web 2.0 on user added value

\begin{tabular}{|l|l|}
\hline Sources/Factors of User-added value & Impact of Web 2.0 \\
\hline User-Generated Content & $\begin{array}{l}\text { Creation of profiles, whole websites, and media } \\
\text { (e.g. YouTube), forced businesses to integrate } \\
\text { new applications to meet second generation In- } \\
\text { ternet user demands. }\end{array}$ \\
\hline User-Generated Creativity & $\begin{array}{l}\text { Web 2.0 Internet user tends to proactively bring } \\
\text { in a whole new perspective on established pro- } \\
\text { cesses and approaches, so that, users create in- } \\
\text { novative ideas for the future development of } \\
\text { companies. }\end{array}$ \\
\hline User-Generated Innovations & $\begin{array}{l}\text { E.g. the huge amount of innovations in the } \\
\text { 'open software' industry. }\end{array}$ \\
\hline Sources of Revenue & $\begin{array}{l}\text { 2nd generation Internet user activities enable } \\
\text { companies to optimize and broaden their prod- } \\
\text { uct range. }\end{array}$ \\
\hline
\end{tabular}

\section{Objective \& Methodology}

\subsection{Objective of the Study}

To the best of our knowledge, the systematic literature review by [55], (referred to it also in [57]), is the only available review that, dealt with the same topic in this paper, Viz., web 2.0 in the innovation process. The indicated review was more on $\mathrm{B} 2 \mathrm{~B}$ use of social media in the innovation context. It was conducted using the databases Scirus, ABI, Emerald, ScienceDirect and EBSCO with the search term combinations, businessto-business and social media / web 2.0, b2b and social media / web 2.0, customer interaction and social media / web 2.0, customer understanding and social / web 2.0, customer knowledge and social media / web 2.0, cocreation and social media / web 2.0, customer knowledge management, and CRM 2.0 / social CRM. The total of (1357) articles were first received and then they were skimmed for relevance.

Some additional references were also discovered by searching forward and backward referencing of the most relevant articles. In addition, searches were performed concerning individual web 2.0 -related tools, such as wikis, blogs, twitter, LinkedIn, etc. in the specific context of B2B and the customer interface using various combinations of search terms and above research databases.

In this paper, the review aims to systematically assess the evolution of the literature and the extent to which it addressed web 2.0 in the innovation process since the emergence of these technologies. The paper also attempts to identify, web2.0 tools addressed and their association in the literature with the various aspects and stages of the innovation process, as well as, the significant trends, in 
scholarly studies, in dealing with the mentioned topic.

The present paper adds to the only available prior study and it represents another step toward developing a better understanding of the state of the literature with regard to social software in the innovation process. The review herein contributes in the following ways. It covers the entire period that extends from the beginning of the emergence of social software and Web 2.0 technologies to the year 2012. It also utilizes a broader range of keywords and covers a wide range of social software tools. Additionally, it is not oriented only toward the literature addresses web 2.0 from the perspective of business-to-business companies' innovation. Furthermore, the study here adopted a different systematic approach for the literature review which is the principle of lexical analysis.

\subsection{Literature Search \& Analysis Method}

A keyword search against two categories, the documents' title, and abstract, was performed for scholarly literature, published in the period from 2002 - 2012 and covering the two topics, innovation and social software. The search utilized "Business source premier", in an effort to keep the search, as far as possible, focused in literature in the areas of business and management. Nevertheless, and with this focus in mind, other literature databases were also explored, in order not to narrow the search process if limited to one database only. These databases included Emerald and the subject area of Business, Management and Accounting in the database of ScienceDirect.

The search keywords encompassed different aspects and stages of the innovation process and made use of [58] (Table 2). Also, a keyword list of social software tools (Table 3) was developed with making use of [39] [40] [41] [43] [59] [60] [61].

Table 2. Innovation

\begin{tabular}{|l|l|}
\hline Innovation & Creativity \\
\hline New Product development & Research and Development \\
\hline Problem Solving & Suggestion Systems \\
\hline Idea Generation & Commercialization \\
\hline Invention & Time To Market \\
\hline Divergent Thinking & Lead User \\
\hline Stage Gate & First To Market \\
\hline Fuzzy Front End & Convergent Thinking \\
\hline Adoption Curve & \\
\hline
\end{tabular}

Table 3. Web 2.0

\begin{tabular}{|l|l|}
\hline Web 2.0 & Social Software \\
\hline Mashups & Information Markets \\
\hline Internet Forums & $\begin{array}{l}\text { Massively Multiplayer Online Role Playing } \\
\text { Games }\end{array}$ \\
\hline Really Simple Syndication & Discussion Forums \\
\hline Social Tagging & Instant Messaging \\
\hline Iowa Electronic Markets & Discussion Boards \\
\hline Prediction Markets & Social Bookmarking \\
\hline Web Forums & Collaborative Tagging \\
\hline Folksonomy & Blogs \\
\hline Weblogs & Online Social Networks \\
\hline Podcast & Wiki \\
\hline
\end{tabular}


The variables identified in the literature for the analysis, were as follows, Cat (Innov for articles collected on innovation \& SS for articles on social software), title, abstract, and year. After removing all duplicates, the total number of articles collected was 6106 articles (4145 articles in the innovation category, and, 1961 in the social software category).

As indicated earlier, the principle of lexical analysis was employed for the purpose of this literature review. 'Lexical analysis offers a middle-ground between quantitative and qualitative analysis, being rapidly applicable to texts of all types, and giving a far more flexible interface between the tasks of data acquisition, analysis and interpretation. This approach is typified by the calculation of "word lexicons": lists of words and their corresponding frequencies in the corpus' [62]. The lexical analysis here adhered to the following procedures throughout:

the two variables (Title, Abstract) are combined in a single variable (Tit\&AbstCombined), in order to examine the title and abstract of each article simultaneously;

the set of search keywords was developed into a dictionary (a dictionary is a list of terms which describes a certain theme), in which each keyword is grouped with its different variations and synonyms found in the corpus and is represented in the form (\#keyword), where (keyword) is the name assigned to the group. That means that, a group (\#keyword) counted only once, if any of the variations and synonyms belonging to it, is repeated, and/or if found together, in the same article. This is done so that, frequencies are based on observations rather than on occurrences. In other words, frequencies herein represent the number of articles referring to a certain group or (\#keyword);

the frequency of (\#keyword) is ignored if it is zero.

\section{Results}

Based on the above-indicated procedures, and in order to distil from the literature, articles likely to be relevant, namely, those containing at the same time, innovation and so- cial software \#keywords; an analysis was performed on the variable (Tit\&AbstCombined) in all articles. Accordingly, all articles do not contain, neither in their titles nor in their abstracts, any of social software \#keywords, were removed from the innovation category (Innov), and likewise, all articles do not contain, neither in their titles nor in their abstracts, any of innovation \#keywords were removed from the social software category (SS).

The number of articles identified in the above first step was 260 articles. In the next step, all extracted articles were screened by reading through their titles and abstracts to eliminate irrelevant articles. Apparently, the selection criteria were that, the article must address social media or web 2.0, and relate to innovation in general, or to some or to all innovation process phases. Ultimately, the total number of resulting articles to be included in the literature review (hereinafter, referred to as, the Web 2.0 - Innovation articles), was 99 articles.

\subsection{Web 2.0 - Innovation articles}

The number of Web 2.0 - Innovation articles found in the literature (which represents about $1.6 \%$ of the total number of articles collected on the two topics of web 2.0 and innovation) (Figure 1), shows that, the study of web 2.0 tools in the innovation process has been given some, but, however, not a great deal of attention in the literature. This clearly suggests that, there is still much more room for further research in this specific area in order to advance our knowledge of the role that web 2.0 technologies can play in enhancing and supporting collaborative efforts and initiatives within the innovation process. This particularly important in light of, on the one hand, the hype surrounding web 2.0 as a new generation of web based technologies [18] [63] [64]. On the other hand, as outlined above, the increasing importance in today's environment of collaboration in the innovation process, and, the indispensable role of information technology (IT) tools, particularly, web based technologies, in enabling such collaboration across different boundaries. 


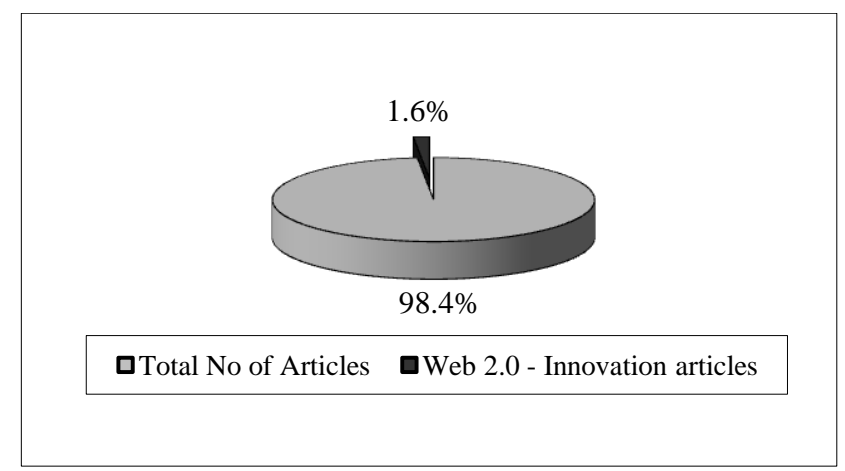

Fig. 1. Percentage of web 2.0-innovation articles in the literature

5.2 Web 2.0 - Innovation articles / Year

As Figure 2 shows, the modest attention given to web 2.0 tools in the context of the innovation process has fluctuated over the period 2002-2012. Actually, this attention may be considered to have really started in the year 2007. Then, in the period between the year 2008 and 2010, there was a relative increase in the number of articles published on the indicated topic. However, on the contrary, the number of the articles began to drop after the year 2010, which is the year with the highest number of articles along the period included in this analysis. This, in fact, goes very much in line with the result, reached by [65], in his analysis of web 2.0 literature in the period between 2002-2012, which indicates that, there was a growing interest in web 2.0 that reached its peak in the year 2010, but, the tide of interest seemed to be ebbing over the two years 2011/12, as there was a noticeable and steady decrease in the number of articles.

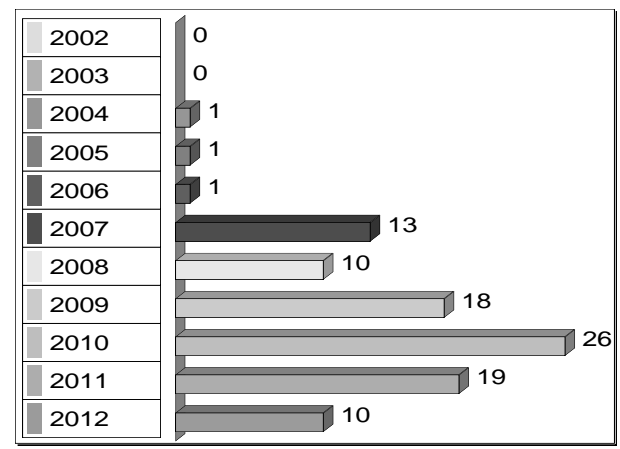

Fig. 2. Web 2.0 - innovation articles / year

\subsection{Web 2.0: Innovation articles/Web tools}

A little more than the third, of the total number of Web 2.0 - Innovation articles (36 articles), referred to web 2.0 in general, and did not include, any reference to any specific web 2.0 tool. As to the rest 63 articles, the results indicate that, \#blogs and \#wiki were the tools most addressed in relation with the innovation process and were referred to in (17 and 14 articles, respectively). 'In addition to their public uses of the web, wikis and blogs are becoming important corporate tools for communication, collaboration, and infor- mation sharing [66]'. These two tools were followed in order by, \#prediction markets, \#discussion forums and \#online social networks (Facebook, Twitter and so on), with a frequency of (12, 11, 8 articles respectively). The three tools least addressed were \#instant messaging (5 articles), followed by, \#Podcasts and \#Bookmarking or tagging tools (3 articles each). No reference was found to \#Massively Multiplayer Online Games, mashups and RSS, Figure 3. 


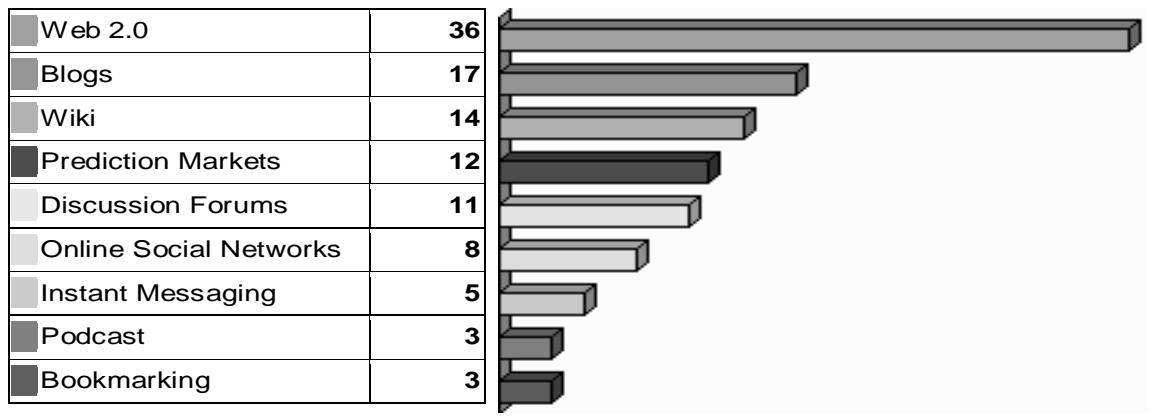

Fig. 3. Web 2.0 - innovation articles / web 2.0 tools

\subsection{Web 2.0 - Innovation articles / Aspects of the Innovation Process}

The innovation process involves various activities and stages [67]. Having explored the web 2.0 tools addressed in the web 2.0-innovation articles; the next lines look at the other side of the coin, namely, the aspects and stages of the innovation process covered in these articles.

The frequencies in Figure 4 below show that, the various aspects and stages within the innovation process were addressed in varying degrees in the literature. The term \#creativity was the most frequent and found in 16 articles. This clearly shows that, a special attention in the limited literature available on web 2.0 in the innovation process was paid to creativity, which is, in the words of [68], 'the seed of all innovation'. The next in order was the innovation phase or area of \#new product develop- ment (NPD) process, which was referred to in 12 articles. Following that, is the \# problem solving process and was referred to in 11 articles. The frequency of \#idea generation which is a key element within the innovation process was 9 articles. As to the source of innovation, so-called by Eric Von Hippel "\#lead users" [69], it was cited by 7 articles. The three least aspects addressed were successively as follows, \#research and development (R\&D), which is a key driving force of innovation (5 articles), the innovation phase of \#commercialisation (4 articles) and the term \#adoption curve (only 1 article). It should be noted, however, that nearly half of the total number of Web 2.0 - Innovation articles (47 articles) related to the innovation process in general and did not include any reference to a certain specific aspect or phase within this process.

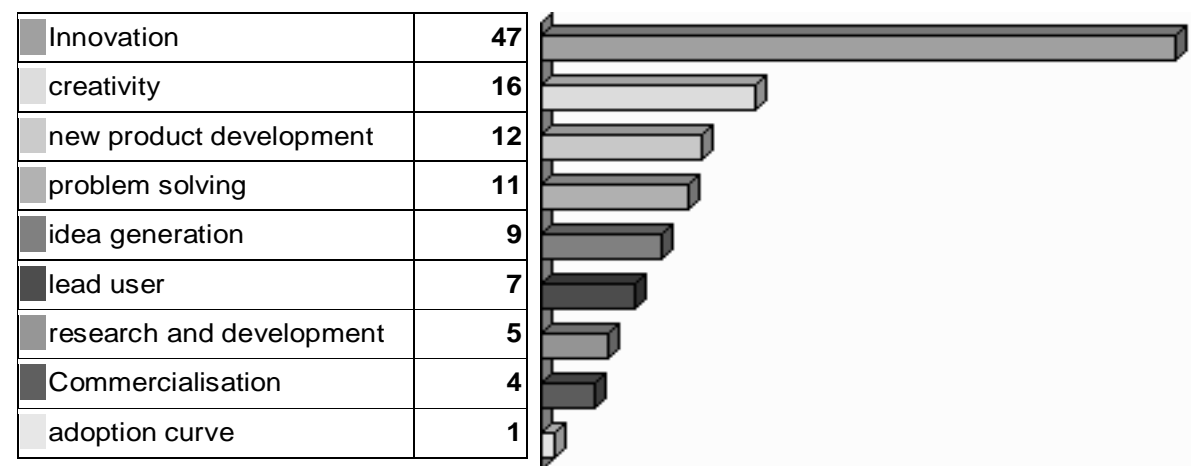

Fig. 4. Web 2.0 - innovation articles / aspects of the innovation process

5.5 Web 2.0 - Innovation articles / Association between web 2.0 tools \& Aspects of the Innovation Process

This subpart gives an overall picture of the trends in the literature in terms of exploring and examining the use and behaviour of the different web 2.0 tools in the different innovation activities and stages. In other words, it explores the association in web 2.0 - innovation articles between the different web 2.0 tools and the various aspects and stages of the innovation process (which web 2.0 tool in which area of innovation?).

The association illustrated below in Table 4 and the factor map Figure 5, shows a variety of limited and scattered research efforts on 
the potential of the different specific web 2.0 tools when used within certain aspects of the innovation process. In our view, it is important to address this shortcoming in the lit-

erature as, on the one hand, the innovation process involves various stages and activities, and, on the other hand, each tool has its own characteristic potentials and pitfalls.

Table 4. Association Web2.0 * Innovation

\begin{tabular}{|c|c|c|c|c|c|c|c|c|c|}
\hline & 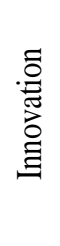 & : & $\begin{array}{l}\stackrel{0}{0} \\
: \\
0 \\
0 \\
0 \\
\frac{0}{0} \\
0 \\
0 \\
0\end{array}$ & 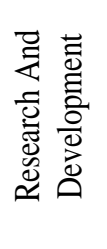 & 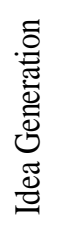 & 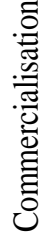 & 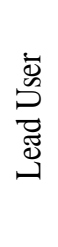 & 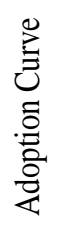 & 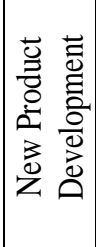 \\
\hline Web 2.0 & 17 & 9 & 3 & 0 & 2 & 0 & 2 & 0 & 4 \\
\hline $\begin{array}{l}\text { Online Social } \\
\text { Networks }\end{array}$ & 4 & 2 & 0 & 0 & 0 & 0 & 1 & 0 & 2 \\
\hline Wiki & 7 & 1 & 4 & 1 & 1 & 1 & 0 & 0 & 1 \\
\hline $\mathrm{B} \log \mathrm{s}$ & 6 & 3 & 1 & 0 & 1 & 0 & 5 & 1 & 4 \\
\hline Podcast & 2 & 0 & 0 & 0 & 0 & 0 & 0 & 1 & 0 \\
\hline Bookmarking & 3 & 0 & 0 & 0 & 0 & 0 & 0 & 0 & 0 \\
\hline Prediction Markets & 4 & 0 & 2 & 5 & 1 & 3 & 0 & 0 & 1 \\
\hline Discussion Forums & 5 & 2 & 2 & 0 & 3 & 0 & 0 & 1 & 1 \\
\hline Instant Messaging & 4 & 0 & 0 & 0 & 1 & 0 & 0 & 0 & 0 \\
\hline
\end{tabular}

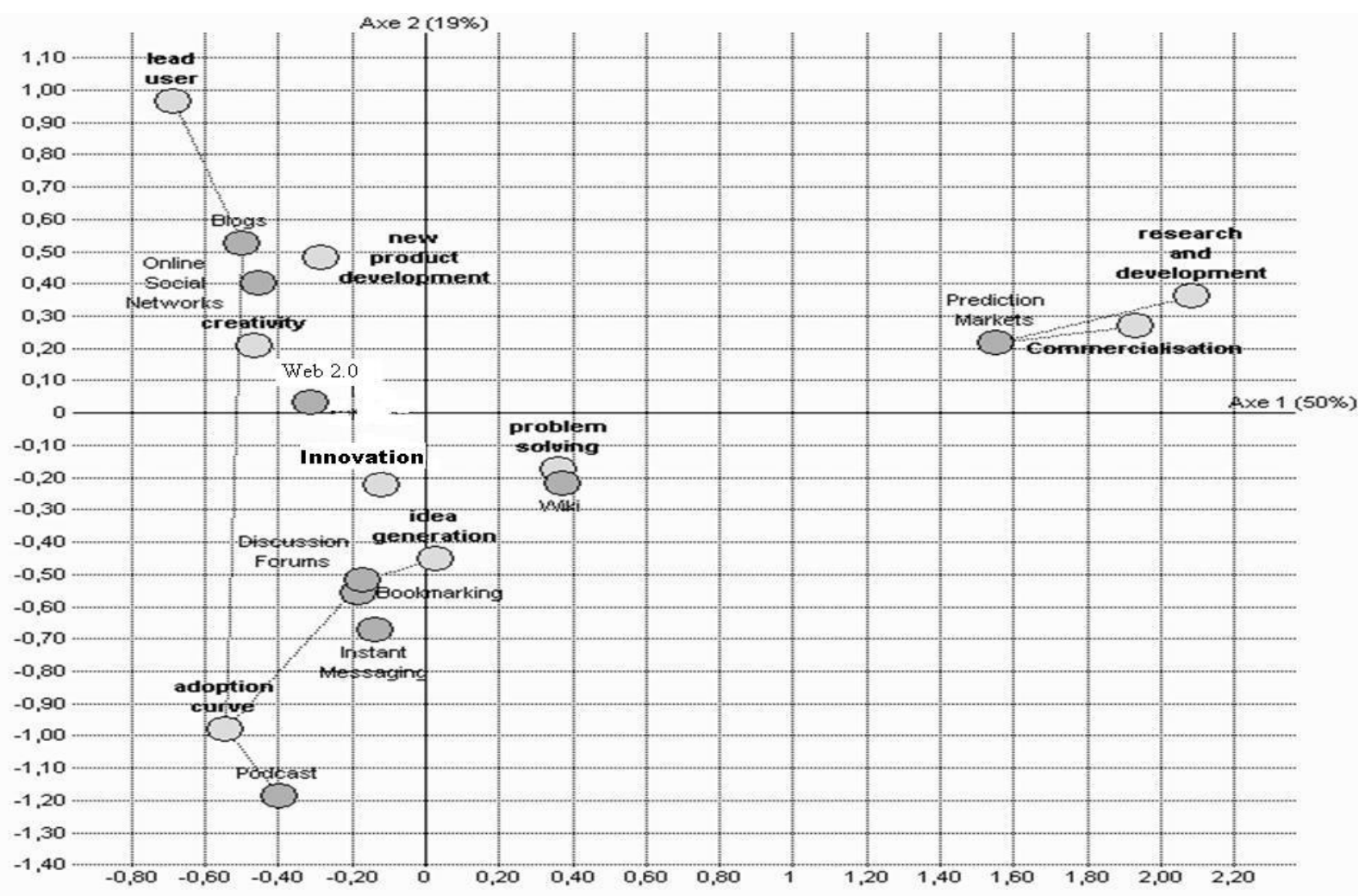

Fig. 5. Association between web 2.0 tools $\&$ aspects of the innovation process 
5.6 Web 2.0 - Innovation articles / Characteristic Words

A search excluding "stop words" (e.g. an, on, of, the...etc.), words containing a number and words of fewer than two letters, was performed on the variable (Tit\&AbstCombined), for the most characteristic words in the web
2.0 - innovation articles. The results illustrated in Figure 6, give a general feel of trends in the literature. (Thresholds were set to show, terms with a minimum frequency of 5 for the whole corpus, and, only the 10 most frequent words).

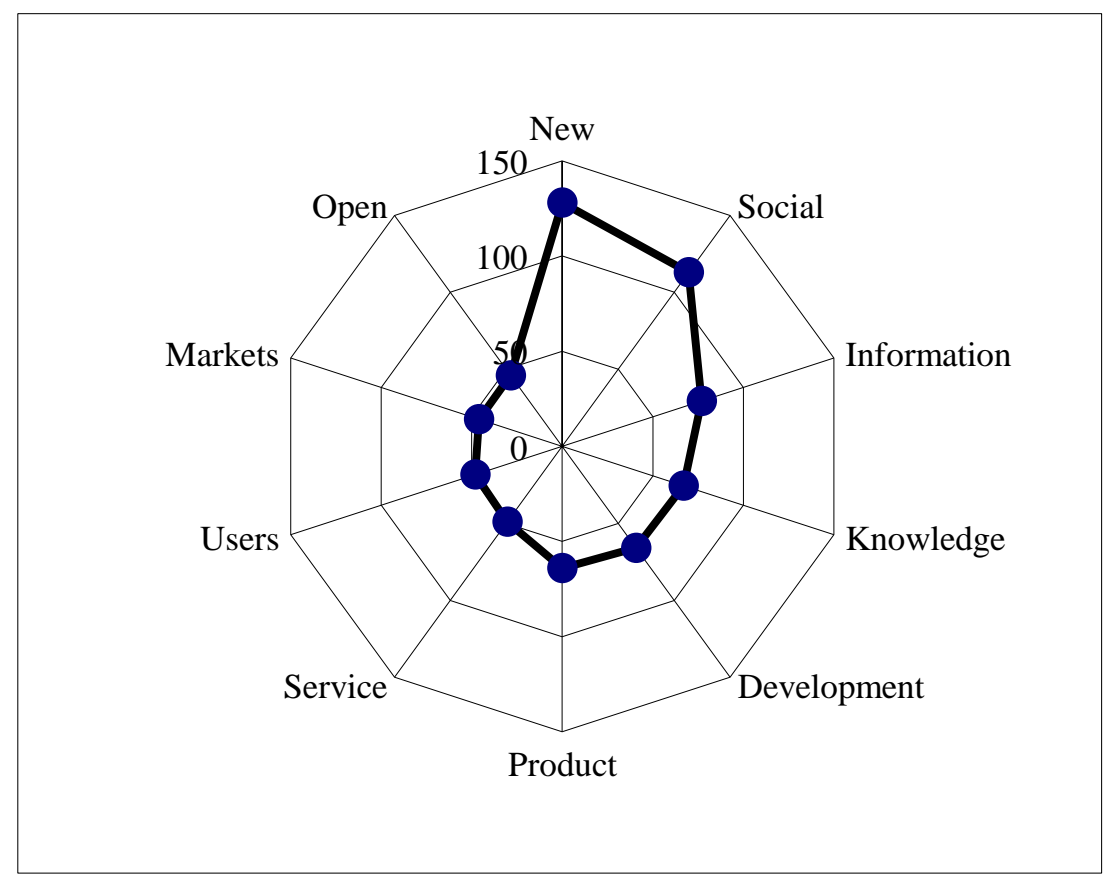

Fig. 6. Most characteristic words in web 2.0 - innovation articles

\section{Conclusions}

This paper shed some light on the importance of collaboration in the innovation process and ITs, web-based, in particular, as a key enabler and facilitator of such collaboration. Specifically, in this context, it focuses on the web-based tools known as web 2.0 or social software and draws attention to the special characteristics, and the increasing interest and use, of these tools to support and enhance collaboration in the innovation process. In this respect, the paper systematically reviews scholarly literature dealing with the role and potentials of web 2.0 tools in the innovation process. It provides an overview of, the status of the literature on this topic, and, its evolution since the emergence of these new technologies. It also attempted to identify, tools addressed, their association with the various aspects and stages of the innovation process, as well as the significant trends in the literature.
The literature review employed the principle of lexical analysis, which is, a simple principle that consists of, applying quantitative analysis to the graphical forms present in a text; a "graphical form" represents a continuous character string containing no separating character. Studying the statistical distribution of these forms enables the production of summaries and the identification of "significant" trends [62] [70].

Overall, the results reveal that, investigating web 2.0 tools in the innovation process is still limited and in its infancy. It is also worth indicating that, the literature displays varying degrees, in addressing the various web 2.0 tools, and it remains particularly poor on exploring these different tools when used in the different aspects or stages of the innovation process. These conclusions clearly suggest that, much more work needs to be done to explore the relation of web 2.0 tools with the innovation process. 
Indeed, the unique characteristics of web 2.0, offer new ways for work, and open up for web users, new opportunities for interaction and collaboration [71] [72] [73] [74]. Therefore, exploring the real potentials, of this new generation of webbased tools, for the key process of innovation, is an important subject that deserves more attention and more investigation. Also, importantly, there is a need for more specific examination of the various web 2.0 tools' benefits and shortcomings for the different innovation activities. After all, on the one side, there is heterogeneity between the different types of social software applications. These application types diverge considerably in terms of characteristics, functionalities, and the objectives that they try to achieve [75]. On the other side, innovation is characterized by being a multi-stage process [76] and a heterogeneous activity [77]. Hence, from this perspective, web 2.0 tools are presumably not "one size fits all" as far as the innovation process is concerned, and as [78], for example, put it, 'the introduction of any tool into an environment has the potential to serve as a catalyst for change. Whether the net value of the resulting change will be positive or negative is highly dependent on how well matched the tool is to the needs of the intended users. As any developer can tell you, there are a lot of ways for a product to fail, and those products intended to help the NPD process are no exceptions'

The approach of lexical analysis is limited to determining the frequencies of words and expressions in a certain text. Therefore, future work will aim for both, a more in-depth analysis, and, a more thorough review, of the limited number of web 2.0-innovation articles found in the literature. The articles will be analyzed using the approach of content analysis, by which articles are to be codified and analyzed according to theoretical categories.

\section{Acknowledgement}

The author thanks Le Sphinx as this research is conducted with their technical support and their software (Sphinx Plus2 - Edition Lexi$c a$ v. 5.0.1.5).

\section{References}

[1] J. Fagerberg, Innovation: A Guide to the Literature. In D. C. Mowery \& R. R. Nelson (Eds.), The Oxford handbook of innovations (pp. 1-26), (2006), Oxford University Press.

[2] P. W. Hyland, R. C. Beckett, Innovation and Enhancement of Enterprise Capabilities: A Survey of Assessment Approaches. International Journal of Technology Management and Sustainable Development, (2004), 3(1), 781 35-46.

[3] G. J. Tellis, Unrelenting Innovation: How to Create a Culture for Market Dominance. Jossey-Bass, (2013)

[4] J. Andrew, J. Manget, D. Michael, A. Taylor, H. Zablit. Innovation 2010: A Return to Prominence - and the Emergence of a New World Order. 2010. The Boston Consulting Group

[5] OECD. Science, technology and industry outlook, (2006), ISBN 92-64-02848-X

[6] OECD. Science, technology and industry outlook,

(2012). http://www.oecd.org/sti/sti- outlook2012-highlights.pdf

[7] O. Adiguzel, A. Figlali, A model for improving organizational innovation. Management of Engineering and Technology, Portland International Conference (PICMET), Portland, USA: (2001, July), Vol.1. 45 - 46.

[8] V. Parida, M. Westerberg, ICT use for innovation in Swedish industrial service SMEs. In H. Haapasalo \& P. Iskanius (Eds.), the 1st Nordic Innovation Research Conference-(2007), Finnkampen, Oulu, Finland: 167-180

[9] D. Rodriguez, D. Solomon, Leadership and Innovation in a Networked World, innovations, (Summer), (2007), 3-13

[10] G. Bafoutsou, G. Mentzas, Review and Functional Classification of Collaborative Systems, International Journal of Information Management, (2002), 22, 281305.

[11] R. E. Miles, C. C. Snow, G. Miles, 
Thefuture.Org. Long Range Planning, (2000), 33, 300-321

[12] R. Rothwell, Successful industrial innovation: critical factors for the 1990s. R\&D Manage ment, (1992), 22(3), 221240.

[13] M. Dodgson, D. M.Gann, A. J. Salter, The intensification of innovation, International Journal of Innovation Management (IJIM), (2002), 6(1), 53-83.

[14] O. Gassmann, Opening up the innovation process: towards an agenda. R\&D Management, 2006, 36(3), 223-228.

[15] A. Johri, H. J. Teo, Assessing the Effectiveness of Open Organizing as a Model for Re-designing Design Learning. International Journal of Engineering Education, (2012), 28(2), 374

[16] P. Wynarczyk, P. Piperopoulos, M. McAdam, Open innovation in small and medium-sized enterprises: An overview. International Small Business Journal, (2013), 31(3), 240-255

[17] E. Prandelli, G. Verona, D. Raccagni, Diffusion of Web-Based Product Innovation. California Management Review, (2006), 48(4), 109-135.

[18] M. Grossman, R. V. McCarthy, Web 2.0: Is The Enterprise Ready For The Adventure?. Issues in Information Systems, (2007), VIII (2), 180-185.

[19] K-Y. Huang, N. Choi, L. Horowitz, Web 2.0 Use and Organizational Innovation: A Knowledge Transfer Enabling Perspective. AMCIS 2010 Proceedings, 2010, Paper 189. http://aisel.aisnet.org/amcis2010/189

[20] N. Errasti, I. Santos , O. Lizarralde, Social Software in Support of Collaborative Innovation Processes, Proceedings of ERIMA 2010, 11-12th June 2010, Wiesbaden, GERMANY, 169-176

[21] J. Meyer, Does social software support service innovation?, International Journal of the Economics of Business, (2010), 17(3), 289-311.

[22] M. Paukert, C. Niederée, C. Muscogiuri, M. Hemmje, P. Bouquet, Knowledge in the innovation process: An empirical study for validating the innovation knowledge life cycle. In F. McGrath \& D. Remenyi (Eds.), Proceedings of the 4th European Conference on Knowledge Management (ECKM), Oxford University, 2003, September, UK: 725-740

[23] C. Muscogiuri, M. Paukert, C. Niederée, M. Hemmje, Dimensions of innovation: Knowledge-based resource mediation for innovation process engineering. In D. Remenyi (Eds.), Proceedings of the 5th European Conference on Knowledge Management (ECKM), Paris, France: 2004, September, Vol. 1. 629-640

[24] M-C. Lee, T. Chang, Linking Knowledge Management and Innovation Management in E-Business. International Journal of Innovation and Learning, 2007, 4(2), 145-159.

[25] A. Deverell, A. H. Lassen, The Challenge of Managing Knowledge in Innovative Organizations: Internal Versus External Knowledge Acquisition. In B. Donnellan, T. Larsen, L. Levine \& J. DeGross (Eds.), International Federation for Information Processing (IFIP) TC8 WG 8.6 International Working Conference: Vol. 206. The Transfer and Diffusion of Information Technology for Organizational, Galway, Ireland, 2006, June, 157-178.

[26] IBM Global Services, Expanding the Innovation Horizon: The IBM Global CEO Study: IBM Corporation, 2006.

[27] J. Tidd, a Review of Innovation Models, Imperial College London, Tanaka Business School, 2006.

[28] H. Chesbrough, Open innovation: A new paradigm for understanding industrial innovation. The Druid Tenth Anniversary Summer Conference on Dynamics of Industry and Innovation: Organizations, Networks and Systems, 2005, June, Copenhagen,

Denmark. http://www2.druid.dk/conferences/viewp aper.php?id=2784\&cf $=18$

[29] K. Blomqvist, J. Levy, Collaboration Capability - A Focal Concept in Knowledge Creation and Collaborative Innovation in Networks. Int. J. Management Concepts and Philosophy, 2006, 
2(1), 31-48.

[30] C. Edquist, M-L. Eriksson, H. Sjögren, Characteristics of Collaboration in Product Innovation in the Regional System of Innovation of East Gothia European. European Planning Studies, 2002, 10(5), 563-581.

[31] K. Gareis, W. B. Korte, ICTS and the adaptability of work arrangements in the EU, The Xth European Conference on Information Systems (ECIS), Gdansk, Poland, 2002, June, 1101- 1112

[32] C. Bayona-Sáez, T. G. Marco, The repercussions of the adoption of information technology on co-operative innovation. In S. Martinez-Fierro, J. A. M. Garrido \& J. R. Navarro (Eds.), Utilizing information technology in developing strategic alliances among organizations, 2006, 122-152. Idea Group Publishing ISBN: 1591408938

[33] M. Ozer, Information Technology and New Product Development: Opportunities and Pitfalls. Industrial Marketing Management, 2000, 29, 387-396.

[34] S. Nambiisan, Designing virtual customer environments for new product development: toward a theory. Academy of Management Review, 2002, 27(3), 392413.

[35] B. W. Wirtz, O. Schilke, S. Ullrich, Strategic Development of Business Models, Long Range Planning, 2010, 43, 272290

[36] L. S. Lai, E. Turban, Groups formation and operations in the Web 2.0 environment and social networks. Group Decision and Negotiation, 2008, 17(5), 387402.

[37] C. Allen, Innovation \& Social Software: Presentation, NVHA Innovations Conference, Social Network Media, 2005, February.

http://Web.Lifewithalacrity.Com/Christo phera/Fvha_Social_Software_Keynote_P resentation.Pdf

[38] M. Ahonen, K. Lietsala, Managing service ideas and suggestions - information systems in innovation brokering. Innovation in Services Conference, (2007,
April), Tekes, Haas business school, Berkeley, California

[39] J. Secker, Social software, libraries and distance learners: literature review, 2008, Project Report, LSE, London, (Unpublished).http://eprints.lse.ac.uk/4058/ 1/LASSIE_lit_review\%28LSERO\%29.p df

[40] L. Zhang, Adoption of social software for collaboration. Doctoral thesis, 2010, October, University of Manchester, UK

[41] D. T. Green, J. M. Pearson, Social software and cyber networks: Ties that bind or weak associations within the political organization?. Proceedings of the 38th Hawaii International Conference on System Sciences (HICSS), 2005, Jan, 117b $117 \mathrm{~b}$

[42] I. Nonaka, A Dynamic Theory of Organizational Knowledge Creation. Organization Science, 1994, 5(1), 14-37.

[43] S. V. Z. Anria, The impact of Social Networking 2.0 on organisations, The Electronic Library, 2009, Vol. 27 Iss: 6 pp. $906-918$

[44] M. Koch, CSCW and Enterprise 2.0towards an integrated perspective, 2008, 21th Bled eConference, eCollaboration: Overcoming Boundaries through MultiChannel Interaction.

[45] M. Steinhüser, S. Smolnik, U. Hoppe, Measuring the Success of Social Software Adoption in the Firm: Empirical Evidence and Model Design. International Journal of Social and Organizational Dynamics in IT (IJSODIT), 2012, 2(2), 34-47.

[46] G. Avram, at the crossroads of knowledge management and social software, Academic Conferences Ltd, 2005

[47] J. Vinson, There is something about social software, Blog, Knowledge Jolt with Jack, 2005http://blog.jackvinson.com/ archives/2005/04/29/there_is_something _about_social_software.html

[48] B. R. Katzy, C. J. Stettina, L. P. Groenewegen, M. J. de Groot, Managing weak ties in collaborative work. In Concurrent Enterprising (ICE), 2011 17th International Conference (pp. 1-9). 2011, 
June, IEEE

[49] A. Stocker, A. Richter, P. Hoefler, K. Tochtermann, Exploring Appropriation of Enterprise Wikis, Computer Supported Cooperative Work (CSCW), 2012, 1-40.

[50] K. Riemer, A. Richter, SOCIALEmergent Enterprise Social Networking Use Cases: A Multi Case Study Comparison, Business Information Systems, Working Paper Series, 2012, ISSN 18371744, University of Sydney.

[51] N. Drakos, J. Mann, A. Sarner, Gartner's 2012 Magic Quadrant for Social Software in the Workplace. The web conferencing blog, 2013, http://davidchao. typepad.com/webconferencingexpert/201 3/03/gartners-2012-magic quadrant-forsocial-software-in-the-workplace.html

[52] The McKinsey Quarterly, McKinsey Global Survey Results: Building the Web 2.0 Enterprise, July 2008.

[53] J. de Kraker, R. Cörvers, P. Valkering, M. Hermans, J. Rikers, Learning for sustainable regional development: towards learning networks 2.0?. Journal of Cleaner Production, 2013, 49 114-122

[54] A. Tran, S. ul Hasan, J. Park, Crowd Participation Pattern in the Phases of a Product Development Process that Utilizes Crowdsourcing. Industrial Engineeering \& Management Systems, 2012, 11(3), 266-275.

[55] H. Kärkkäinen, J. Jussila, J. Janhonen, Managing customer information and knowledge with social media in businessto-business companies, Proceedings of the 11th International Conference on Knowledge Management and Knowledge Technologies, 2011, September, p. 17, ACM

[56] J. Jussila, H. Kärkkäinen, M. Leino, 'Learning from and with customers with social media: a model for social customer learning', International Journal of Management, Knowledge and Learning, 2012, Vol. 1, No. 1, pp.5-25.

[57] J. Jussila, H. Kärkkäinen, M. Leino, Benefits of social media in business-tobusiness customer interface in innovation. In Proceedings of the 15th Interna- tional Academic MindTrek Conference: Envisioning Future Media Environments, 2011, September, 167-174, ACM.

[58] PDMA, Glossary for New Product Development, 2008. http://ebookbrowse.com/pdma-glossaryof-npd-terms-080319-doc-d369938176

[59] M. N. K. Boulos, S. Wheeler, The Emerging Web 2.0 Social Software: An Enabling Suite of Sociable Technologies in Health and Health Care Education. Health Information and Libraries Journal, 2007, 24, 2-23.

[60] D. W. Wilson, X. Lin, P. Longstreet, S. Sarker, "Web 2.0: A Definition, Literature Review, and Directions for Future Research", 2011, AMCIS 2011 Proceedings_Paper 368. http://aisel.aisnet.org/amcis2011_submiss ions $/ 368$

[61] Social software, Wikipedia, the free encyclopedia, 2013 http://En.Wikipedia.Org/Wiki/Social_Sof tware

[62] J. Moscarola, R. Bolden, from the data mine to the knowledge mill: Applying the principles of lexical analysis to the data mining and knowledge discovery process. Paper presented at The Second European Symposium on Principles of Data Mining and Knowledge Discovery, 1998, September, Nantes, France.

[63] J. Secker, C. Lloyd, Libraries, social software and distance learners: The adventures of LASSIE. Health Info on the Internet, 2008, 62(1), 6-8.

[64] S. De Hertogh, S. Viaene, Encouraging the Mindful Consideration of Enterprise 2.0: Design and Deployment of a GDSSSupported Collaborative Strategic Episode. System Science (HICSS), 45th Hawaii International Conference, 2012, January, 3858-3868, IEEE.

[65] L. Altamimi, a Lexical Analysis of Social Software Literature, Informatica Economică Jounal, 2013, vol. 17, no. 1

[66] K. Schwertner, Modern Information Technology (IT): Factor for Business Efficiency and Business Driver. Journal of Modern Accounting and Auditing, 2013, 
9(8), 1131-1139

[67] J. Rundquist, The ability to integrate different types of knowledge and its effect on innovation performance, International Journal of Innovation Management, 2012, 16(02)

[68] T. M. Amabile, R. Conti, H. Coon, J. Lazenby, M. Herron, Assessing the Work Environment for Creativity. Academy of Management Journal, 1996, 39(5), 11541184.

[69] E. V. Hippel, the Sources of Innovation, 1988. New York: Oxford University Press.

[70] J. Moscarola, Contribution of Qualitative Methods to Research in Work and Organizational Psychology: Sphinx Lexica and MCA, 2002, June, Communication to ISSWOV 2002, VARSAW.

[71] D. Gendarmi, F. Lanubile, Communitydriven ontology evolution based on folksonomies. In On the Move to Meaningful Internet Systems 2006: OTM 2006 Workshops, 2006, 181-188, Springer Berlin/Heidelberg.

[72] K. Stepanyan, R. Mather, J. Payne, Integrating Social Software into Course Design and Tracking Student Engagement: Early Results and Research Perspectives, World Conference on E-Learning in Corporate, Government, Healthcare, and Higher Education, 2007, October, Vol. 2007, No. 1, 7386-7395.

[73] A. Eardley, L. Uden, the Use of 'Web 2.0'and Social Software in Support of Professional Learning Communities. Innovative Knowledge Management: Concepts for Organizational Creativity and Collaborative Design, 2010, 204

[74] A. Soyland, J. Herstad, A tale of two trajectories: bottom-up social software adoption in differing organisational contexts. International Journal of Internet and Enterprise Management, 2011, 7(3), 305-321.

[75] P. Raeth, S. Smolnik, N. Urbach, C. Zimmer, Towards Assessing the Success of Social Software in Corporate Environments, 2009, AMCIS 2009 Proceedings, Paper 662. http://aisel.aisnet.org/amcis2009/662

[76] G. Kortuem, F. Kawsar, Market-based user innovation in the internet of things, Internet of Things (IOT), 2010, 1-8, IEEE.

[77] E. Martínez-Ros, V. Salas-Fumás, Do workers share innovation returns? A study of the Spanish manufacturing sector, Management Research: the Journal of the Iberoamerican Academy of Management, 2004, 2(2), 147-160

[78] L. P. Cooper, A research agenda to reduce risk in new product development through knowledge management: a practitioner perspective, Journal of Engineering and Technology Management. JETM, 20, 2003, 117-140.

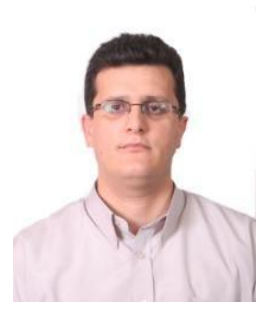

Loay ALTAMIMI has graduated the Faculty of Economic and administrative sciences in 1996. He holds a PhD diploma in Management Information Systems from 2010. He works as assistant professor at the Al-Zaytoonah University of Jordan, Department of MIS. He is also a certified professional trainer (CPT) and a member of the Jordanian Trainers Society (JTS). His research interests include collaborative information systems and web surveys. 